Check for updates

Cite this: RSC Adv., 2018, 8, 406

Received 23rd October 2017 Accepted 4th December 2017

DOI: 10.1039/c7ra11720e

rsc.li/rsc-advances

\title{
The study on continuous denitrification, desulfurization of pyrolusite/activated coke hybrid catalyst $\uparrow$
}

\begin{abstract}
Lin Yang, (D) ${ }^{a}$ Lu Yao, ${ }^{\text {ab }}$ Wenju Jiang, ${ }^{\text {ab }}$ Xia Jiang ${ }^{\text {ab }}$ and Jianjun Li ${ }^{\mathrm{ab}}$
In this study, the industrial application of pyrolusite/activated coke hybrid catalysts (ACP) for continuous $\mathrm{SO}_{2}$ and NO removal was simulated and studied systematically. The obtained results show that the denitrification process of ACP before $\mathrm{SO}_{2}$ removal had almost no influence on its desulfurization activity even though the surface functional groups showed variation. The denitrification property of ACP, however, significantly enhanced after desulfurization and regeneration. The NO removal efficiency of ACP increased from $74.2 \%$ to $100 \%$ and remained relatively stable, and the $\mathrm{N}_{2}$ selectivity was higher than $90.2 \%$. The formed metal sulfate $\left(\mathrm{MnSO}_{4}\right.$ and $\left.\mathrm{Fe}_{2}\left(\mathrm{SO}_{4}\right)_{3}\right)$, showed the catalytic activity, which synergistically worked with surface functional groups to improve the selected catalytic reduction (SCR) of NO. However, large quantity of the formed metal sulphates restricted the mass transfer on the surface of ACP, which caused the reduction of desulfurization performance and the hypothesis of NO conversion of ACP-Rn.
\end{abstract}

\section{Introduction}

With the significant efforts contributed from the national and local government for air pollution control in recent years, the sulphur oxides $\left(\mathrm{SO}_{x}\right)$ and nitric oxides $\left(\mathrm{NO}_{x}\right)$ emission, which primarily caused the acid rain, photochemical smog and haze pollution, ${ }^{1-3}$ has been effectively controlled and the environmental quality greatly improved across China. However, a further control on the emission of such compounds is needed because of the implementation of new Ambient Air Quality Standards (GB 3095-2012), which reported a more strict emission limitation on almost all pollutants. Therefore, improvements in desulfurization and denitrification of the flue gas (FGD), the most common purification method of the sintering exhaust, are still an important challenge for air quality improvement.

After years of survey and investigation, significant amount of funds and effort have been devoted to develop new technologies and materials in order to control the emission of $\mathrm{SO}_{2}$ and $\mathrm{NO}_{x}$.

${ }^{a}$ College of Architecture and Environment, Sichuan University, Chengdu 610065, P. R. China.E-mail:wenjujiang@scu.edu.cn; xjiang@scu.edu.cn

${ }^{b}$ National Engineering Research Center for Flue Gas Desulfurization, Chengdu 610065, P. R. China

$\dagger$ Electronic supplementary information (ESI) available: Fig. S1 the diagram of the denitrification and desulfurization system. Fig. S2 the $\mathrm{N}_{2}$ adsorption-desorption curves of the ACP and ACP-Rn. Fig. S3 the wide-scan XPS spectrums of the ACP-Rn. Fig. S4 the C 1s curves deconvolution of the ACP and ACP-Rn before and after NO removal. Fig. S5 the Mn 2p and Fe 2p curves deconvolution of the ACP and ACP-Rn before and after denitrification. Fig. S6 the NO removal curves of the ACP-400-Rn. See DOI: 10.1039/c7ra11720e
Activated coke (AC), a high efficiency and low cost porous carbon material, has obtained increasing attention in recent decades because it can be control the emission of $\mathrm{SO}_{2}, \mathrm{NO}_{x} ;{ }^{\mathbf{4 - 6}}$ as well as the heavy metal/toxic waste. ${ }^{7,8}$ However, the issue of deactivation of catalytic activity of $\mathrm{AC}$ due to formation of $\left(\mathrm{NH}_{4}\right)_{2} \mathrm{SO}_{4} / \mathrm{NH}_{4} \mathrm{HSO}_{4}$ during the simultaneous removal of $\mathrm{SO}_{2}$ and $\mathrm{NO}_{x}$ has not been dealt effectively; ${ }^{6}$ which limits its applicability significantly because of the decreased activity and increased operation cost. ${ }^{9}$ Therefore, the reactor designers usually divide the moving bed reactor into two parts (upper and bottom section) to ensure the high efficiency of purification. The bottom section is used to remove $\mathrm{SO}_{2}$, heavy metals and toxins, while the upper section is used for denitrification. The flue gas, primarily containing $\mathrm{SO}_{2}, \mathrm{NO}_{x}$, and other toxic gases, is introduced into the system from the bottom to first remove $\mathrm{SO}_{2}$, toxic gases and most of the steam, and then completely remove $\mathrm{NO}_{x}$ by passing $\mathrm{NH}_{3}$ or $\mathrm{CO}$ in the upper section. ${ }^{\mathbf{1 0}}$ The direction of AC flow is kept opposite to that of the flue gas; AC enters the top of reactor and first removes NO, and then descends to the bottom section to remove $\mathrm{SO}_{2}$, air toxins and steam. After $\mathrm{NO}$ and $\mathrm{SO}_{2}$ removal, the $\mathrm{SO}_{2}$ /toxics-filled $\mathrm{AC}$ is discharged and sent to the regenerator, and then back to the purification plant for reuse of AC after regeneration. Unfortunately, almost all of the previous research were based on only the desulfurization and denitrification separately ${ }^{11}$ or simultaneously by AC, ${ }^{12,13}$ nobody had studied the continuous desulfurization and denitrification of AC, which is essential for industrial applications. Tsuji et al. had reported that the NO removal efficiency increased from 45.0 to $80.0 \%$ when $\mathrm{AC}$ was regenerated after $\mathrm{NO}$ and $\mathrm{SO}_{2}$ removal, ${ }^{\mathbf{1 4}}$ but they only described the variation of NO removal activity, and 
there was no mention of why the NO removal efficiency improved and its mechanism. It was reported that the physicochemical properties of AC constantly change with continuous usage, it is important to point out what the reciprocities of these two process and how it works.

Moreover, researchers have also made quantity of efforts to improve activity and reduce preparation cost of AC in order to make it more suitable for industrial application. ${ }^{15}$ Among these technologies, surface modification by loading transition metals attracted great attention. ${ }^{6,16}$ Natural minerals, rich in transition metals, showed great prospect due to its relatively low cost and the simple preparation procedure when it used as precursor, ${ }^{17}$ and the catalytic activity and stability of some kinds of natural minerals for $\mathrm{SO}_{2}$ and $\mathrm{NO}$ removal also have been proved. ${ }^{18,19}$ However, it is noteworthy that the formation of metal sulphates during the desulfurization process on the surface of modified $\mathrm{AC}$ is unavoidable for almost all the transition metals, and they are difficult to be decomposed under commonly used regeneration temperatures $\left(\leq 500{ }^{\circ} \mathrm{C}\right) .{ }^{20}$ In our previous research, we had discussed the effects of $\mathrm{MnSO}_{4}$ on $\mathrm{SO}_{2}$ removal over $\mathrm{MnO}_{2}$ modified AC by lending method (i.e. $\mathrm{Mn}_{4} / \mathrm{AC}$ ). ${ }^{21}$ However, what the effects of the formed metal sulphates on NO removal of such hybrid carbon-based catalyst are still unknown. Therefore, it has as great theoretical significance and practical value (in terms of industrial applications) to study the continous application of AC for denitrification and desulfurization.

In this study, pyrolusite/activated coke catalyst (ACP) was prepared by the blending modification of fresh AC. The continuous denitrification and desulfurization property of prepared sample was investigated on a lab-scale to evaluate its potential for industrial applications. The structure properties and surface chemistry were characterized by BET, XPS, XRD and FTIR. The metal sulphate impregnated AC (AC-IM) and dilute sulphuric acid treated AC (AC-DSC) were prepared to investigate the functions of metal sulphate and surface functional groups formed on regenerated ACP after NO and $\mathrm{SO}_{2}$ removal, which are helpful to point out the reciprocities and the work mechanism between these two processes.

\section{Materials and methods}

\subsection{Preparation of activated coke}

In this study, two types of coal as raw carbon materials, coal tar as binder and pyrolusite as catalyst precursor were used to prepare the pyrolusite-doped AC (ACP); the approximate elemental analysis of the two types of coal and coal tar are listed in Table 1. Pyrolusite used in this study majorly consists of Mn

Table 1 Main ingredients of raw materials and main binder (\%)

\begin{tabular}{|c|c|c|c|c|c|c|c|c|}
\hline \multirow[b]{2}{*}{ Samples } & \multicolumn{4}{|c|}{ Proximate analysis } & \multicolumn{4}{|c|}{ Elemental analysis } \\
\hline & $\mathrm{M}_{\mathrm{ad}}$ & $A_{d}$ & $\mathrm{~V}_{\mathrm{d}}$ & $\mathrm{FC}_{\mathrm{d}}$ & $\mathrm{C}_{\mathrm{ad}}$ & $\mathrm{H}_{\mathrm{ad}}$ & $\mathrm{N}_{\mathrm{ad}}$ & $\mathrm{S}_{\mathrm{ad}}$ \\
\hline Bituminous c & 0.85 & 11.83 & 34.11 & 54.06 & 73.78 & 9.69 & 2.29 & 1.76 \\
\hline $1 / 3$ coking coal & 1.32 & 2.74 & 35.55 & 61.71 & 74.23 & 4.83 & 2.08 & 0.47 \\
\hline
\end{tabular}

(39.40\%), Fe (6.27\%), Si (4.10\%), Ca (1.30\%), Ni (0.07\%), Cu $(0.06 \%)$ and Co $(0.06 \%)$. The ACP preparation is almost similar to our previous study; ${ }^{19}$ the difference is that the blending ratio of pyrolusite is $10.0 \mathrm{wt} \%$. The metal sulphate impregnated AC (AC-IM) was prepared by equivalent-volume impregnation method. Initially, $3.0 \mathrm{wt} \%$ of $\mathrm{MnSO}_{4}$ (AR grade) and $0.6 \mathrm{wt} \%$ of $\mathrm{Fe}_{2}\left(\mathrm{SO}_{4}\right)_{3}$ (AR grade) based on the weight ratio of AC sample were simultaneously dissolved in deionized water. AC was soaked in sulphate solution for $24 \mathrm{~h}$ to ensure uniformity of mixture. Following this, the mixture was first dried in a water bath at $60{ }^{\circ} \mathrm{C}$ for $2 \mathrm{~h}$ to release most of the water, and then placed in an oven at $105{ }^{\circ} \mathrm{C}$ overnight. The dilute sulphur acid treated AC (AC-DSC) was also prepared by equivalent volume impregnation method. Fresh AC was immersed in dilute sulphuric acid over $24 \mathrm{~h}$ to obtain $10 \%$ loading ratio of sulphur acid, and then dried in an oven at $105{ }^{\circ} \mathrm{C}$ overnight. Following this, the sulphur acid impregnated $\mathrm{AC}$ was calcined at $500{ }^{\circ} \mathrm{C}$ for $60 \mathrm{~min}$ in $\mathrm{N}_{2}$ atmosphere to simulate the regeneration of AC after $\mathrm{SO}_{2}$ removal.

\subsection{Characterization of activated coke}

Nitrogen adsorption capacity of ACs was measured using ASAP 2460 analyser (Micromeritics, USA) at $77 \mathrm{~K}$. The samples were degassed at $523 \mathrm{~K}$ for $8 \mathrm{~h}$ before analysis. The specific surface areas (SSA) were calculated using Brunauer-Emmett-Teller equation..$^{22}$ The total pore volume was estimated with respect to the liquid volume of $\mathrm{N}_{2}$ adsorbed at a relative pressure of 0.995 . The micropore $\left(V_{\text {mic }}\right)$ volume and micropore surface area (MSA) were obtained by $t$-plot theory. The mesopore volume $\left(V_{\text {mes }}\right)$ was determined by Barret-Joyner-Halenda (BJH, adsorption) model. $\mathrm{X}$-ray photoelectron spectroscopy (XPS) characterization of the surface was carried out on a XSAM-800 spectrometer (KRATOS, $\mathrm{UK})$ with $\mathrm{Al}-\mathrm{K} \alpha$ radiation $(1486.60 \mathrm{eV}$ ) under ultra-high vacuum; the source was operated at $12 \mathrm{kV}$ and $15 \mathrm{~mA}$. Energy calibration was carried out by recording the core level spectra of $\mathrm{Au} 4 \mathrm{f}_{7 / 2}$ $(84.00 \mathrm{eV})$ and $\mathrm{Ag} 3 \mathrm{~d}_{5 / 2}(368.30 \mathrm{eV})$. High-resolution scans (0.10 $\mathrm{eV})$ were recorded over the range of $278.00-294.00 \mathrm{eV}$ (C 1s), 630.00-665.00 eV (Mn 2p) and 700.00-738.00 eV (Fe 2p). The crystal structure of activated coke was determined by X-ray diffraction (XRD) using an X-Pert PRO MPD diffractometer (Panalytical, NL) employing $\mathrm{CuK} \alpha$ radiation at $30 \mathrm{kV}$ and $20 \mathrm{~mA}$ and step-scanning over $2 \theta$ range of $10.00-80.00^{\circ}$. The crystalline phases were identified by comparison with the reference data from the International Center for Diffraction Data (JCPD). The Fourier-Transform Infrared Spectroscopy (FTIR) characterizations were carried out in the $4000-400 \mathrm{~cm}^{-1}$ region with a spectrometer (FTIR 6700, Nicolet, USA) at a resolution of $2 \mathrm{~cm}^{-1}$.

\subsection{Desulfurization, denitrification and regeneration}

The denitrification and desulfurization activity tests were carried out on a lab-scale fixed-bed reactor system (Fig. S1†). The conditions and operation of $\mathrm{SO}_{2}$ removal test were same as our previous study, ${ }^{19}$ the simulated flue gas contains $3000 \mathrm{ppm}$ of $\mathrm{SO}_{2}, 8.0 \%$ of $\mathrm{O}_{2}, 10.0 \%$ of steam and $\mathrm{N}_{2}$ as balance gas. The NO removal test of the activated coke was carried out under 
$150{ }^{\circ} \mathrm{C}$ with the space velocity of $1000 \mathrm{~h}^{-1}$. The simulated flue gas flow contains $500 \mathrm{ppm}\left(670 \mathrm{mg} \mathrm{m}^{-3}\right)$ of NO, $550 \mathrm{ppm}$ (417 $\mathrm{mg} \mathrm{m}^{-3}$ ) of $\mathrm{NH}_{3}, 5.0 \%$ of $\mathrm{O}_{2}$ and $\mathrm{N}_{2}$ as the balance gas. Before the catalytic reduction of $\mathrm{NO}$ with $\mathrm{NH}_{3}$, all samples were saturated with adsorbed NO at the same conditions of denitrification in order to eliminate the adsorption effect. The selective catalytic reduction (SCR)-based NO removal was initiated when the inlet and outlet concentrations of NO were equal. The inlet and outlet $\mathrm{SO}_{2}$ and $\mathrm{NO}$ were monitored online by Testo 350, and the $8 \mathrm{~h}$ NO removal efficiency was defined as the activity index. For $\mathrm{N}_{2}$ selectivity calculation, the inlet and outlet gas composition were analysed by FT-IR analysis (Antaris IGS-6700, Nicolet Thermo Fisher Scientific). The $\mathrm{NO}$ and $\mathrm{SO}_{2}$ removal were simulated by static experiments in order to get uniform samples. The regeneration of $\mathrm{SO}_{2}$ captured ACP was carried out at $500{ }^{\circ} \mathrm{C}$ for $60 \mathrm{~min}$ in $\mathrm{N}_{2}$ atmosphere $\left(100 \mathrm{~mL} \mathrm{~min}^{-1}\right)$, and the heating rate of regeneration was $5{ }^{\circ} \mathrm{C} \mathrm{min}^{-1}$. The regenerated catalyst-sorbent was labelled as ACP-Rn, and its name was updated as ACP-Rn-NO after denitrification.

\section{Results and discussion}

\subsection{The continuous denitrification and desulfurization performance}

The NO removal efficiency of fresh and regenerated ACP (ACP and ACP-Rn) are shown in Fig. 1a. It can be observed that the NO conversion of the fresh ACP is $74.2 \%$, which significantly improved after continuous $\mathrm{NO}$ and $\mathrm{SO}_{2}$ removal and regeneration, and the improvement showed a linear increase with the increase of regeneration cycles. The NO removal efficiency increased to $93.8 \%$ after one regeneration cycle (ACP-R1), which is $19.6 \%$ higher than that of ACP. After three times of regeneration (ACP-R3), the NO removal efficiency was higher than 99.5\% and remained relatively stable with further reuse. This result is clearly consistent with the previous studies that the NO removal activity was enhanced when $\mathrm{AC}$ was regenerated after $\mathrm{SO}_{2}$ removal. ${ }^{\mathbf{1 4 2 3}}$ The $\mathrm{N}_{2} \mathrm{O}$ concentration in the outlet gas remained stable in the range from 30 to $35 \mathrm{ppm}$ (53-62 $\mathrm{mg} \mathrm{m}^{-3}$ ), and the corresponding $\mathrm{N}_{2}$ selectivity was higher than $90.2 \%$. It was reported that the coexistence of $\mathrm{Mn}$ and Fe can accelerate the electron transfer and promote $\mathrm{NH}_{3}$ activation, which is favourable for the reaction between the NO and $\mathrm{NH}_{3} \cdot{ }^{24}$ However, it is interesting that the ACP-Rn needs a longer working time to reach a stable NO removal activity than that of fresh ACP, and showed a strong dependence on the number of regeneration cycles. This hysteresis of NO reduction in the previous stage of denitrification could be caused by the metal sulphate generated during the desulfurization process, but this is just our deduction. The real reason and mechanism of the hysteresis is still unclear.

The desulfurization breakthrough curves of ACP and ACP-Rn after NO removal are shown in Fig. 1b. The breakthrough working time of ACP-Rn-NO linearly reduced after each regeneration cycle. The ACP-Rn, however, still had a relatively high activity for $\mathrm{SO}_{2}$ removal after five times of regeneration; the $100 \% \mathrm{SO}_{2}$ removal time of ACP-R5 was still longer than $8 \mathrm{~h}$. The sulphur capacity of ACP-R5 was $71 \mathrm{mg} \mathrm{g}^{-1}$; which is significantly higher than that for many non-regenerated AC samples reported earlier. ${ }^{25,26}$ The same variation was reported by Guo et al.; the group found that the desulfurization performance of the used catalyst-sorbent linearly decreased, while its NO removal efficiency clearly improved. ${ }^{27}$ The excellent NO removal activity and improved desulfurization performance illustrate that the used pyrolusite-modified AC (ACP) synthesized by the blending method is a good low temperature desulfurization and denitrification catalyst.

\subsection{Physicochemical analysis of the regenerated ACP}

3.2.1 Specific surface area and porosity. The $\mathrm{N}_{2}$ adsorption-desorption of the used ACs were investigated to evaluate the influence of continuous denitrification, desulfurization and regeneration on their structure properties; the $\mathrm{N}_{2}$ adsorptiondesorption curves are depicted in Fig. S2. $\uparrow$ Table 2 lists the calculation based on the analysis. The surface area (SSA) of AC is $479 \mathrm{~m}^{2} \mathrm{~g}^{-1}$, which decreased to $454 \mathrm{~m}^{2} \mathrm{~g}^{-1}$ after the first cycle of application and then remained stable after the second


Fig. 1 NO conversion (a) and desulfurization breakthrough curves (b) of ACP-Rn. 
Table 2 Textual properties of activated coke samples ${ }^{a}$

\begin{tabular}{|c|c|c|c|c|c|c|}
\hline Samples & $\operatorname{SSA}\left(\mathrm{m}^{2} \mathrm{~g}^{-1}\right)$ & $\operatorname{MSA}\left(\mathrm{m}^{2} \mathrm{~g}^{-1}\right)$ & $V_{\text {tot }}\left(\mathrm{cm}^{3} \mathrm{~g}^{-1}\right)$ & $V_{\text {mic }}\left(\mathrm{cm}^{3} \mathrm{~g}^{-1}\right)$ & $V_{\text {mes }}\left(\mathrm{cm}^{3} \mathrm{~g}^{-1}\right)$ & $R_{\text {mean }}(\mathrm{nm})$ \\
\hline $\mathrm{ACP}$ & 479 & 385 & 0.277 & 0.186 & 0.091 & 2.31 \\
\hline ACP-R1 & 454 & 362 & 0.257 & 0.179 & 0.079 & 2.37 \\
\hline ACP-R3 & 470 & 393 & 0.287 & 0.194 & 0.093 & 2.49 \\
\hline ACP-R4 & 477 & 397 & 0.289 & 0.196 & 0.093 & 2.38 \\
\hline ACP-R5 & 506 & 415 & 0.294 & 0.205 & 0.089 & 2.37 \\
\hline AC-IM & 431 & 346 & 0.245 & 0.170 & 0.075 & 2.27 \\
\hline AC-DSC & 502 & 413 & 0.279 & 0.205 & 0.074 & 2.11 \\
\hline
\end{tabular}

${ }^{a}$ SSA is specific surface area, MSA is micropore surface area, $V_{\text {tot }}$ is total pore volume, $V_{\text {mic }}$ is micropore volume, $V_{\text {mes }}$ is mesopore volume and $R_{\text {mean }}$ is average pore diameter.

regeneration cycle $\left(452 \mathrm{~m}^{2} \mathrm{~g}^{-1}\right.$ of ACP-R2). After that, the SSA linearly increases with the increased reusing cycles and completely recovered after the fourth regeneration cycle (ACPR4) with SSA at $477 \mathrm{~m}^{2} \mathrm{~g}^{-1}$. The total pore volume $\left(V_{\text {tot }}\right)$ and micropore volume $\left(V_{\text {mic }}\right)$ showed the same change trend with SSA and recovered after two cycles of regeneration. In addition, it should be noted that there was almost no change in $V_{\text {mes }}$, which maintained at around $0.090 \mathrm{~cm}^{3} \mathrm{~g}^{-1}$ except for ACP-R1 $\left(0.079 \mathrm{~m}^{3} \mathrm{~g}^{-1}\right)$. The reduction of SSA, $V_{\text {tot }}$ and $V_{\text {mic }}$ in the first few cycles is due to the formation of metal sulphates during the $\mathrm{SO}_{2}$ removal; the removed $\mathrm{SO}_{2}$ primarily transformed to form sulphate, and they could not decomposed at the regeneration temperature. ${ }^{21}$ With the increasing number of regeneration cycles, there is a higher ratio of removed $\mathrm{SO}_{2}$ stored in $\mathrm{AC}$ as sulphur acid. The sulphuric acid, reacting with carbon, played the role of further activation of ACP and improved its porosity. The variation of $V_{\text {mes }}$, shown in Table 2, suggests that the regeneration of ACP at $500{ }^{\circ} \mathrm{C}$ primarily created the micropore structure, and there was no clear pore diameter expansion because the mesopore volume was not clearly changed in the first few regeneration cycles. The relative stable average pore diameter $\left(R_{\text {mean }}\right)$ was a good testimony.

Our previous study showed that the SSA of pyrolusite-doped $\mathrm{AC}$ recovered quickly and then continuously increased for more than 10 reusing cycles. ${ }^{19}$ The slower recovery rate in this study is attributed to the higher blending ratio of pyrolusite; the $10.0 \mathrm{wt} \%$ blending ratio of pyrolusite is 2.5 times higher than the sample used in our previous study $(4.0 \mathrm{wt} \%)$. This indicates that there was higher metal sulphate formation when the ACP was used for $\mathrm{SO}_{2}$ removal. To confirm this deduction, ACP-R5 was washed using deionized water (labelled as ACP-R5W). The BET analysis shows that the SSA and $V_{\text {tot }}$ of ACP-R5W $\left(590 \mathrm{~m}^{2}\right.$ $\mathrm{g}^{-1}$ and $\left.0.327 \mathrm{~cm}^{3} \mathrm{~g}^{-1}\right)$ were dramatically higher than that of ACP-R5 $\left(506 \mathrm{~m}^{2} \mathrm{~g}^{-1}\right.$ and $\left.0.294 \mathrm{~cm}^{3} \mathrm{~g}^{-1}\right)$. The $V_{\text {mes }}$ of ACP-R5W $\left(0.093 \mathrm{~cm}^{3} \mathrm{~g}^{-1}\right)$ conformed with our previous result, indicating that the reaction between the sulphur acid and carbon at $500{ }^{\circ} \mathrm{C}$ only formed some content of micropore structure, and there was no clear pore diameter expansion during the regeneration. In addition, increased micropore volume caused the reduction of $R_{\text {mean }}$ of ACP-R5W $(2.25 \mathrm{~nm})$.
Corroboration of the NO removal activity of regenerated ACP and their structure properties suggests that the SSA and pore structure were not the limiting factors for NO removal because the NO conversion of ACP-R1 and ACP-R2 were significantly higher than that of ACP although their structure properties are worse. The variation of the desulfurization and denitrification could be primarily controlled by their surface chemical properties, such as modification of the functional groups and metals, which would be discussed in the following section.

3.2.2 Surface functional groups. The XPS characterization was carried out to analyse the surface functional groups variation of ACP after continuously used for denitrification and desulfurization; the wide-scanning spectrums of ACP and ACPRn are exhibited in Fig. S3. $\dagger$ For the fresh ACP, only four clear peaks attributed to the $\mathrm{Mn}, \mathrm{Fe}, \mathrm{O}$ and $\mathrm{C}$ were detected, while there was a new peak, which is attributed to sulphur (S 2p), detected on the surface of ACP-Rn. Furthermore, the low intensity new peak corresponding to $\mathrm{N} 1 \mathrm{~s}$ also appeared after three regeneration cycles. The $\mathrm{S} 2 \mathrm{p}$ peak is attributed to the formed metal sulphates after flue gas desulfurization; many previous studies had discussed about this. ${ }^{20}$ The presence of $\mathrm{N}$ 1s could be due to the adsorbed $\mathrm{NH}_{3}$ and $\mathrm{NO}$, particularly the $\mathrm{NH}_{3}$ species, which could react with $\mathrm{H}_{2} \mathrm{SO}_{4}$ to form $\left(\mathrm{NH}_{4}\right)_{2} \mathrm{SO}_{4} /$ $\mathrm{NH}_{4} \mathrm{HSO}_{4}$, and then aminate the coke surface during the high temperature regeneration. ${ }^{28} \mathrm{No} \mathrm{N}$-containing functional groups on the surface of ACP-R1 and ACP-R2 were detected, which indicates that the adsorbed $\mathrm{NO}$ and $\mathrm{NH}_{3}$ participated in SCR NO removal effectively. However, with the increase of regeneration number, the textual properties of activated coke improved (Table 2), which are more favourable for $\mathrm{NO}$ and $\mathrm{NH}_{3}$ adsorption. In addition, there was some amount of adsorbed $\mathrm{NO}$ and $\mathrm{NH}_{3}$ available for the reaction following desulfurization.

To evaluate the variation of surface oxygen-containing functional groups, the binding energy $(\mathrm{BE})$ and relative content (RCs) of ACP and ACP-Rn corresponding to the C 1s spectra (Fig. S4†) are calculated. As summarized in Table 3, the RCs of $\mathrm{C}-\mathrm{C}$ bond on the surface of catalyst-sorbent reduced gradually from $1^{\text {st }}$ to $4^{\text {th }}$ regeneration cycle, and then showed a slight increment with further reuse. However, the content of $\mathrm{C}=\mathrm{O}$ and $\pi-\pi^{*}$ transition peak was higher than that of ACP even though ACP-R5 showed a reduction compared with ACP- 
Table 3 Binding energy (BE) and relative content (RCs) of $\mathrm{C}$ 1s for activated coke

\begin{tabular}{|c|c|c|c|c|c|c|c|c|}
\hline \multirow[b]{2}{*}{ Samples } & \multicolumn{2}{|l|}{$\mathrm{C}-\mathrm{C}$} & \multicolumn{2}{|l|}{$\mathrm{C}-\mathrm{O}$} & \multicolumn{2}{|l|}{$\mathrm{C}=\mathrm{O}$} & \multicolumn{2}{|l|}{$\pi-\pi^{*}$} \\
\hline & $\mathrm{BE}(\mathrm{eV})$ & $\mathrm{RC}(\%)$ & $\mathrm{BE}(\mathrm{eV})$ & $\mathrm{RC}(\%)$ & $\mathrm{BE}(\mathrm{eV})$ & $\mathrm{RC}(\%)$ & $\mathrm{RC}(\%)$ & $\mathrm{BE}(\mathrm{eV})$ \\
\hline $\mathrm{ACP}$ & 284.63 & 70.34 & 285.90 & 19.09 & 287.61 & 6.18 & 289.97 & 4.39 \\
\hline ACP-NO & 284.64 & 68.56 & 285.73 & 19.75 & 28.15 & 6.24 & 289.47 & 5.45 \\
\hline ACP-R1 & 284.65 & 69.95 & 285.80 & 18.02 & 287.32 & 7.08 & 289.49 & 4.96 \\
\hline ACP-R1-NO & 284.65 & 67.87 & 285.79 & 19.59 & 287.14 & 7.10 & 289.16 & 5.43 \\
\hline ACP-R2 & 284.63 & 67.08 & 285.93 & 19.06 & 287.39 & 8.84 & 289.40 & 5.03 \\
\hline ACP-R2-NO & 284.60 & 64.57 & 285.98 & 20.03 & 287.70 & 9.26 & 289.76 & 6.14 \\
\hline ACP-R3 & 284.67 & 65.45 & 285.87 & 19.87 & 287.35 & 9.19 & 289.23 & 5.49 \\
\hline ACP-R3-NO & 284.60 & 63.98 & 285.74 & 21.03 & 287.32 & 9.00 & 289.52 & 6.00 \\
\hline ACP-R4 & 284.64 & 65.16 & 286.03 & 18.81 & 287.51 & 9.56 & 289.57 & 6.47 \\
\hline ACP-R4-NO & 284.67 & 63.74 & 286.03 & 20.10 & 287.36 & 9.27 & 289.37 & 6.89 \\
\hline ACP-R5 & 284.63 & 69.14 & 285.94 & 18.83 & 287.59 & 6.24 & 289.16 & 5.79 \\
\hline ACP-R5-NO & 284.66 & 67.28 & 285.92 & 20.76 & 287.42 & 6.02 & 289.28 & 5.95 \\
\hline
\end{tabular}

$\mathrm{R} 4$. The RCs of the $\mathrm{C}-\mathrm{O}$ group initially increased, and then reduced with the number of regeneration cycles; ACP-R3 had the highest content of $\mathrm{C}-\mathrm{O}$ at $20.87 \%$. In general, the RCs of oxygen-containing functional groups of ACP-Rn were higher than those of ACP, which is primarily attributed to the high temperature carbon acid reaction, i.e., $\mathrm{C}+\mathrm{H}_{2} \mathrm{SO}_{4} \rightarrow \mathrm{CO}+\mathrm{CO}_{2}+$ $\mathrm{SO}_{2}+\mathrm{H}_{2} \mathrm{O}$ and the pyrolysis of oxygen containing macromolecules during the regeneration. ${ }^{29,30}$ On comparing ACP/ACP-Rn before and after NO removal, it was found that the RCs of $\mathrm{C}-\mathrm{C}$ showed a certain reduction when the ACP/ACP-Rn was used for NO removal, while the RCs of $\mathrm{C}-\mathrm{O}, \mathrm{C}=\mathrm{O}$ and $\pi-\pi^{*}$ transition peak mildly increased alternatively. This could be attributed to the adsorbed oxygen, which transformed to radical oxygen and expressed as the increment of oxygen-functional groups. It was reported that the catalytic activity for $\mathrm{NO}_{x}$ and $\mathrm{SO}_{2}$ removal of AC-based catalyst could be improved with the increase in the surface oxygen-containing functional groups, ${ }^{28,31}$ and it also proved to be the controlling factor for the $\mathrm{SO}_{2}$ removal of the pyrolusite-doped AC. ${ }^{19}$ The linearly reduced

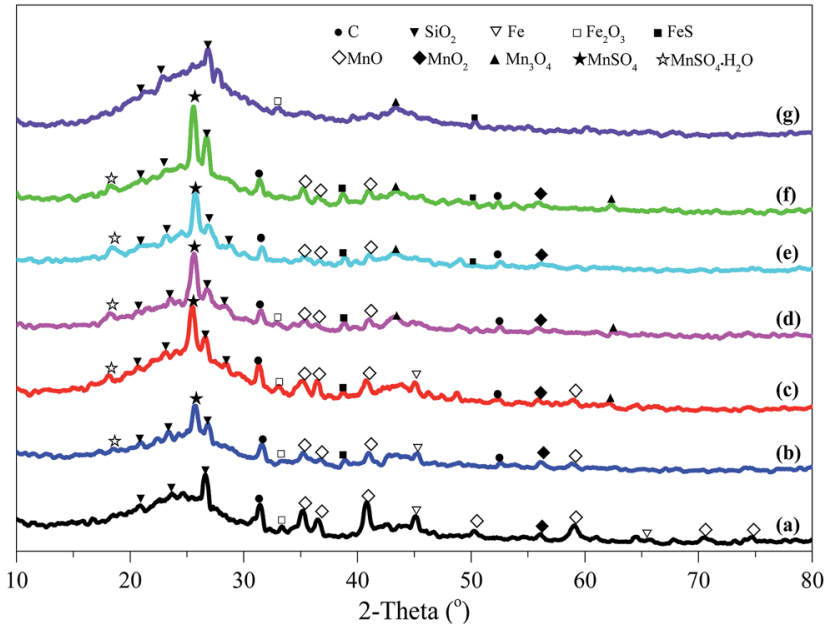

Fig. 2 XRD patterns of cyclically regenerated activated coke. (a) ACP (b) ACP-R1, (c) ACP-R2, (d) ACP-R3, (e) ACP-R4, (f) ACP-R5, (g) ACPR5W. desulfurization performance of ACP-Rn was primarily due to its large content of metal sulphate dispersed on the surface, which limited the catalytic oxidation of $\mathrm{SO}_{2}$ on the surface of catalystsorbent. ${ }^{21}$

3.2.3 Surface metal chemistry. The X-ray powder diffraction (XRPD) of ACP and ACP-Rn was applied to clarify the metal chemistry. As shown in Fig. 2, the detected $\mathrm{SiO}_{2}$ on the surface of all samples is due to the two types of coals and pyrolusite as raw materials, which contain certain amount of $\mathrm{SiO}_{2} \cdot{ }^{11}$ The peaks corresponding to crystalline $\mathrm{MnO}$ (JCPDs no. 75-0257/040326) and $\mathrm{Fe}^{0}$ (JCPD 87-0722) on the surface of ACP imply that manganese and iron oxides in the pyrolusite were reduced in the strong reduction atmosphere under the high activation temperature $\left(900{ }^{\circ} \mathrm{C}\right) .^{21}$ After desulfurization and denitrification, however, $\mathrm{MnO}$ and $\mathrm{Fe}^{0}$ diffraction peaks weakened or even disappeared (ACP-Rn). There were some new peaks corresponding to $\mathrm{MnSO}_{4} \cdot \mathrm{H}_{2} \mathrm{O}\left(2 \theta=18.22^{\circ}\right.$, JCPD 07-0230), $\mathrm{MnSO}_{4}$ $\left(2 \theta=25.32^{\circ}\right.$ (ref. 20$\left.)\right), \mathrm{MnO}_{2}\left(2 \theta=45.26^{\circ}\right.$, JCPD $\left.42-1169\right)$ and $\mathrm{Mn}_{3} \mathrm{O}_{4}\left(2 \theta=42.94^{\circ}, 62.32^{\circ}\right.$, JCPD 13-0162) that were detected. In addition, two small peaks at $2 \theta=38.82^{\circ}, 50.29^{\circ}$ corresponding to FeS were also detected. It is known that the coexistence of $\mathrm{Mn}^{4+}$ and $\mathrm{Fe}^{2+}$ could accelerate the electron transfer, which promote the $\mathrm{NH}_{3}$ activation on the surface of ACP and further accelerate NO removal. ${ }^{24}$ The detected sulphide could be due to reactions between iron oxide and $\mathrm{SO}_{2}$ during the thermal regeneration ${ }^{32}$ under a strong reducing atmosphere along with transition metal catalysts.

The chemical properties of $\mathrm{Mn}$ and $\mathrm{Fe}$ were further confirmed by XPS analysis, and high-resolution Mn 2p and Fe $2 p$ spectra as depicted in Fig. S5. $\dagger$ The metal chemistry of ACPRn changed slightly with continuous application. The peaks of ACP-Rn at around $642.00-642.50 \mathrm{eV}$ and $710.50-711.50 \mathrm{eV}$ were consistent with those of $\mathrm{Mn}^{2+}$ of $\mathrm{MnSO}_{4}$ (ref. 20) and $\mathrm{Fe}^{2+}$ of $\mathrm{FeSO}_{4},{ }^{33}$ respectively. The unclear binding energy shift of Mn $2 \mathrm{p}$ and $\mathrm{Fe} 2 \mathrm{p}$ of ACP-Rn is attributed to the presence of large quantity of metal sulphates, which covered the new exposed metal oxides after regeneration. Fig. 3 shows the highresolution spectrum of sulphur in ACP-Rn to corroborate the metal chemistry. ACP-Rn showed doublet peaks in the BE range 

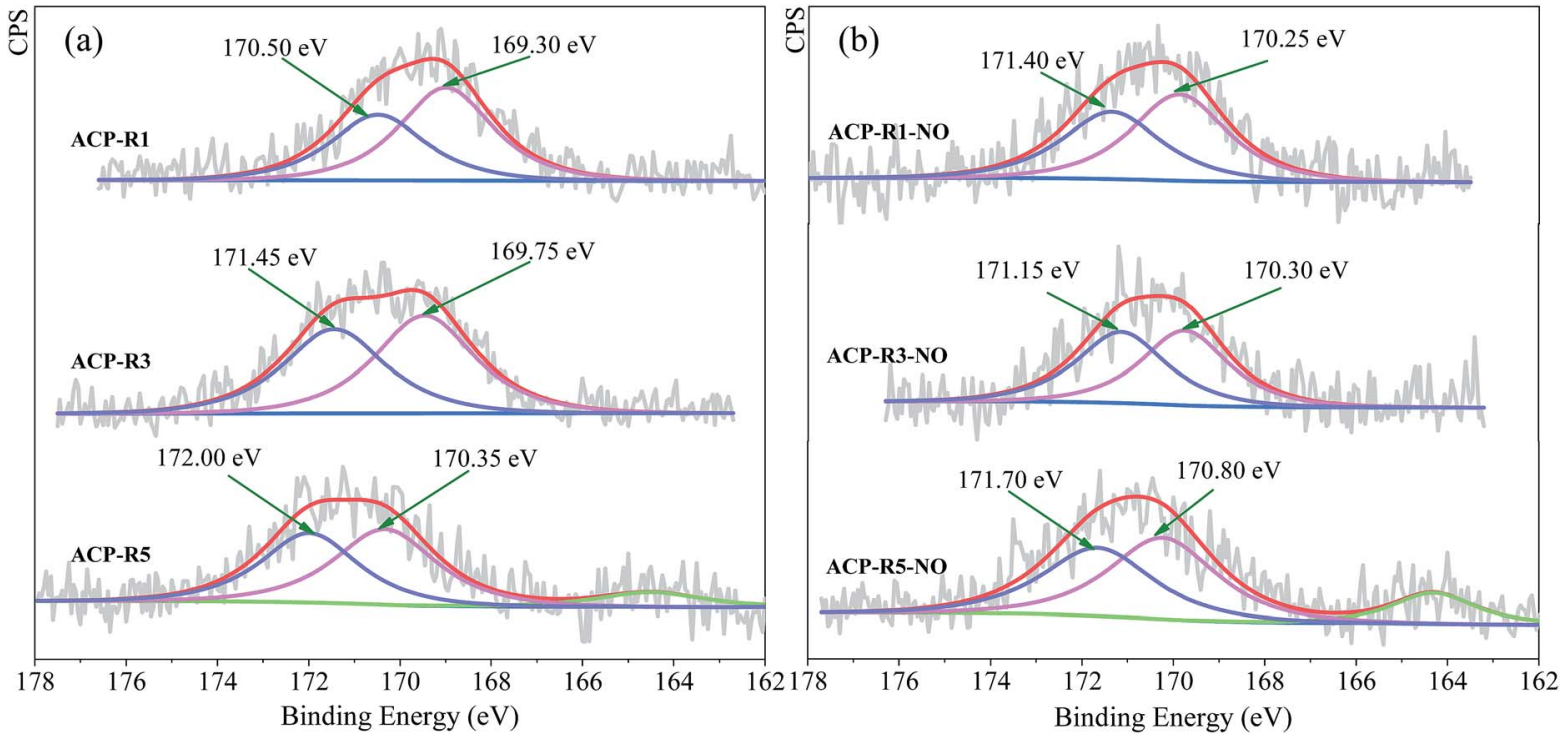

Fig. 3 Deconvoluted S 2p peaks corresponding to ACP-Rn (a) and ACP-Rn post NO removal (b).

of 169.30-172.00 eV, which is normally associated with those of $\mathrm{SO}_{4}{ }^{2-} \cdot{ }^{34}$ The relative higher binding energy was due to the large amount of metal sulphate; ${ }^{35}$ the increase in binding energy with the increase in number of regeneration cycles, 170.50 of ACPR1, 171.45 of ACP-R3 and $172.00 \mathrm{eV}$ of ACP-R5 (Fig. 4a), is good evidence to affirm the above hypothesis.

The comparison of ACP-Rn before and after denitrification suggests that the right B.E. peak shifted to a higher binding energy, while the that on the left reduced slightly after the denitrification except for ACP-R1-NO (Fig. 4b). This could be due to the $\mathrm{NO}, \mathrm{NH}_{3}$ and $\mathrm{O}_{2}$ adsorption during the $\mathrm{NO}$ removal, but this is just a hypothesis and needs a further discussion. In addition, there was no XPS peak corresponding to $\mathrm{S}^{2-}$ (Fig. 3), which could be due to its low content and uniform distribution; also the large content of sulphate covered the surface completely. However, a new peak for ACPR5 and ACP-R5-NO at 164.55 and $164.30 \mathrm{eV}$, respectively, shows the presence of elemental sulphur. ${ }^{36}$ Klinzing et al.



Fig. 4 Sulphur removal capacity of ACP-400-Rn and ACP-Rn before and after denitrification, and before desulfurization. had reported that carbon could react with $\mathrm{SO}_{2}$ to form the elemental sulphur $\left(\mathrm{C}+\mathrm{SO}_{2} \rightarrow \mathrm{S}_{2}+\mathrm{CO}_{2}\right) \cdot{ }^{37}$ Therefore, whether the metals accelerate this reaction needs to be studied further.

\subsection{The reciprocities between denitrification and desulfurization process}

3.3.1 The influence of NO removal on desulfurization. Sulphur removal capacity of the ACP-Rn before and after NO removal, and before desulfurization is shown in Fig. 4. The desulfurization performance of ACP-Rn after NO removal gradually reduced with increasing number of regeneration cycles, while the sulphur removal capacity reduced from $\mathbf{1 3 8 . 5}$ to $71.6 \mathrm{mg} \mathrm{g}^{-1}$ after five using cycles, which is only $58.2 \%$ of the sulphur removal capacity of ACP. The sulphur removal capacity of ACP (without denitrification, ACP-Rn-N) showed the similar change; its sulphur capacity reduced from 138.5 to $72.9 \mathrm{mg} \mathrm{g}^{-1}$. The maximum difference was obtained after the third using cycle, but it was only $6.3 \mathrm{mg} \mathrm{g}^{-1}$, which could be attributed to the experimental error. The ignorable difference of sulphur removal capacity between ACP-Rn and ACP-Rn-N illustrates that $\mathrm{NO}$ removal only had a slight effect on its $\mathrm{SO}_{2}$ removal activity; this finding is well consistent with the previous report. ${ }^{38}$

3.3.2 The influence of desulfurization-regeneration on NO removal. To evaluate the effect of the formed metal sulphates during $\mathrm{SO}_{2}$ removal after $\mathrm{NO}$ reduction, $\mathrm{MnSO}_{4}$ and $\mathrm{Fe}_{2}\left(\mathrm{SO}_{4}\right)_{3}$ co-impregnated AC (AC-IM) was prepared to simulate the regenerated ACP, but without any variation of surface functional groups and metals. As summarized in Table 2, the impregnation of sulphates caused a great reduction of SSA (from 458 to $431 \mathrm{~m}^{2} \mathrm{~g}^{-1}$ ) and pore volume (from 0.267 to 0.245 $\mathrm{m}^{3} \mathrm{~g}^{-1}$ ) of the fresh AC, which would limit the NO removal activity of AC, in theory, because of poor molecular transfer. The AC-IM, however, showed a great efficiency of denitrification (Fig. 5a), whose NO removal efficiency increased to $60.5 \%$, 

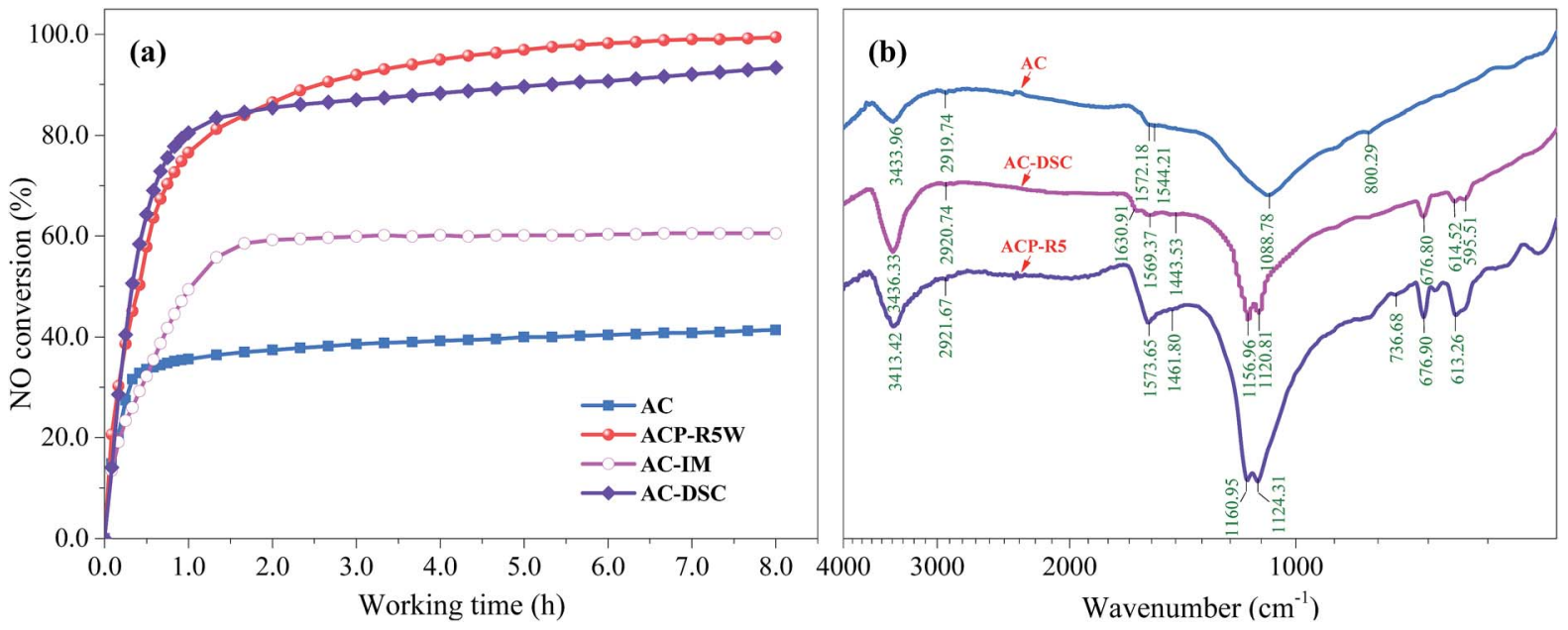

Fig. 5 NO removal activity (a) and FTIR spectra (b) of treated AC, AC-DSC and AC-R5.

which is $19.1 \%$ higher than fresh AC. Such improvement in efficiency reveals that the metal sulphate on the surface of AC enhanced the catalytic reduction of NO. Furthermore, the NO removal curve showed a similar hysteresis for ACP-Rn, which confirmed the coverage effect of metal sulphate.

To further discuss the variation of NO removal activity of ACRn, ACP-R5W was also applied for NO removal. Fig. 5a shows that the NO removal efficiency of ACP-R5W was $99.4 \%$, which was only slightly different compared with ACP-R5; also, the activity hysteresis inevitably weakened. Due to the trace metals on the surface of ACP-R5W (Fig. 2g), the dilute sulphuric acid treated AC (AC-DSC) was prepared to simulate the surface chemistry of regenerated AC. The NO removal efficiency of ACDSC was $93.4 \%$ (Fig. $5 \mathrm{a}$ ), which is $53.0 \%$ and $32.9 \%$ higher than that of fresh AC (40.4\%) and AC-IM (60.5\%), respectively. These results indicate that the improvement of NO removal activity of regenerated ACP was due to the synergistic effect of surface chemistry and metal sulphates, but the surface chemistry played a prominent role for NO reduction than that of metal salts.

It has been reported in literature that sulphur-containing species promote the NO conversion of AC effectively, which could reduce the energy barrier of the catalytic oxidation of $\mathrm{SO}_{2}{ }^{39}$ Therefore, the FTIR characterization of AC, AC-DSC and AC-R5 were carried out and the resultant spectra are depicted in Fig. 5b. It could be observed that there were two new peaks of AC-DSC and ACP-R5 detected at the wavenumber range from 600.00 to $680.00 \mathrm{~cm}^{-1}$. The peaks at 614.52 and $613.26 \mathrm{~cm}^{-1}$ of AC-DSC and AC-R5 attributed to the symmetric and asymmetric stretching vibration of $\mathrm{S}-\mathrm{O}$ or $\mathrm{S}=\mathrm{O}$ in sulphate ion, ${ }^{40}$ while the peaks located at $676.80 \mathrm{~cm}^{-1}$ of AC-DSC and $676.90 \mathrm{~cm}^{-1}$ of ACP-R5 attributed to the $\mathrm{O}=\mathrm{C}=\mathrm{O}$ bond. ${ }^{41}$ Furthermore, the peaks around $1570.00 \mathrm{~cm}^{-1}$ of the AC-DSC and ACP-R5, attributed to the asymmetric stretching vibration of $\mathrm{C}=\mathrm{O}$, had higher intensity. ${ }^{28}$ Such variation of surface chemistry could partially explain the improvement of NO removal by regenerated ACP.

3.3.3 The effect of regeneration temperature. Although the lower regeneration temperature $\left(<500{ }^{\circ} \mathrm{C}\right)$ could not affect the chemistry of metal sulphates, the functional groups would be greatly varied. ${ }^{42}$ Therefore, a new batch ACP was regenerated at $400{ }^{\circ} \mathrm{C}$ (labelled as ACP-400-Rn) after $\mathrm{NO}$ and $\mathrm{SO}_{2}$ removal and was thoroughly analysed to further investigate the influence of surface functional groups. As is shown in Fig. 6, the NO removal capacity of ACP-400-Rn increased with the increase in the number of regeneration cycles, but the increment was lower than that of ACP-Rn, particularly in the first and second reusing cycle, and the stable time of NO removal incontestably became longer (Fig. S6 $\dagger$ ). The NO removal efficiency of ACP-400-R1 and ACP-400-R2 were $77.8 \%$ and $85.4 \%$, which are drastically lower than those of ACP-R1 (93.8\%) and AC-PR2 (97.6\%). The ACP400-R4 had the highest NO removal efficiency (98.6\%). However, the key difference is the slight reduction of NO removal efficiency of ACP-400-R5 compared with ACP-400-R4. This indicates that the activity of regenerated ACP cannot hold with a lower regeneration temperature. The sulphur capacity of ACP-400-Rn was lower than ACP-Rn. The ACP-400-R1 showed the largest reduction; the sulphur removal capacity decreased by $47.7 \mathrm{mg} \mathrm{g}^{-1}$ to $90.8 \mathrm{mg} \mathrm{g}^{-1}$, and the difference



Fig. $68 \mathrm{~h}$ NO conversion of ACP-Rn and ACP-400-Rn. 
became greater with the number of regeneration cycles. These differences reveal that ACP prepared by blending method needs a relatively higher regeneration temperature $\left(500^{\circ} \mathrm{C}\right)$ in order to have a longer life time and high efficiency of reuse.

\section{Conclusion}

Continuous denitrification, desulfurization and regeneration of ACP showed that the NO removal application before desulfurization had almost no influence on the $\mathrm{SO}_{2}$ removal of sample even though the surface functional groups of ACP showed a variation after NO removal. The denitrification property of ACP, however, was significantly improved after the followed desulfurization and regeneration. The NO removal efficiency of ACP-Rn increased from $74.2 \%$ to almost $100 \%$ after three cycles of regeneration, and then remained relatively stable. The $\mathrm{N}_{2}$ selectivities were higher than $90.2 \%$ for all samples. Metal sulphates $\left(\mathrm{MnSO}_{4}\right.$ and $\left.\mathrm{Fe}_{2}\left(\mathrm{SO}_{4}\right)_{3}\right)$, showed catalytic activity for SCR NO removal. The synergistic effect of metal sulphates and surface functional groups improved the SCR NO removal of ACP even though the later one was proved to be more important. However, large quantity of metal sulphate restricted the migration of reactants molecular (i.e. $\mathrm{NO}, \mathrm{NH}_{3}, \mathrm{SO}_{2}$ and $\mathrm{O}_{2}$ ), leading to the reduction in desulfurization activity and the hypothesis of NO conversion at beginning.

\section{Conflicts of interest}

There are no conflicts to declare.

\section{Acknowledgements}

This project is financially supported by the National Natural Science Foundation of China (Project No. 51378324).

\section{Notes and references}

1 I. Mochida, Y. Korai, M. Shirahama, S. Kawano, T. Hada, Y. Seo, M. Yoshikawa and A. Yasutake, Carbon, 2000, 38, 227-239.

2 M. Tao, L. Chen, L. Su and J. Tao, J. Geophys. Res.: Space Phys., 2012, 117, 48-50.

3 W. Li, S. Zhou, X. Wang, Z. Xu, C. Yuan, Y. Yu, Q. Zhang and W. Wang, J. Geophys. Res.: Space Phys., 2011, 116, D09301.

4 S. Ding, Y. Li, T. Zhu and Y. Guo, J. Environ. Sci., 2015, 34, 3743.

5 C. Lu and M. Wey, Fuel Process. Technol., 2007, 88, 557-567. 6 Y. Wang, Z. Huang, Z. Liu and Q. Liu, Carbon, 2004, 42, 445448.

7 Y. Lee, H. Kim, J. Park, B. Choi, D. Choi and J. Park, Carbon, 2003, 41, 1881-1888.

8 P. Davini, Carbon, 2001, 39, 2173-2179.

9 Y. Zhao, R. Hao, T. Wang and C. Yang, Chem. Eng. J., 2015, 273, 55-65.

10 G. O. David, K. Tsuji and I. Shiraishi, Fuel Process. Technol., 2000, 65-66, 393-405.
11 X. Gao, S. Liu, Y. Zhang, Z. Luo and K. Cen, J. Hazard. Mater., 2011, 188, 58-66.

12 Y. Zhao, Y. Han and C. Chen, Ind. Eng. Chem. Res., 2012, 51, 480-486.

13 Y. Guo, Z. Liu, J. Wang, X. Xing and Z. Lei, J. Fuel Chem. Technol., 2008, 36, 36-41.

14 K. Tsuji and I. Shiraishi, Fuel, 1997, 76, 549-553.

15 C.-M. Yang and K. Kaneko, J. Colloid Interface Sci., 2002, 255, 236-240.

16 L. Yang, T. Huang, X. Jiang, J. Li and W. Jiang, RSC Adv., 2016, 6, 55135-55143.

17 L. Yang, X. Jiang, T. Huang and W. Jiang, Environ. Technol., 2015, 36, 2847-2854.

18 L. Yang, W. Jiang, L. Yao, X. Jiang and J. Li, J. Chem. Technol. Biotechnol., 2017, DOI: 10.1002/jctb.5418.

19 L. Yang, X. Jiang, W. Jiang, P. Wang and Y. Jin, Energy Fuels, 2017, 31, 4556-4564.

20 J. Guo, Y. Qu, S. Shu, X. Wang, H. Yin and Y. Chu, New J. Chem., 2015, 39, 5997-6015.

21 L. Yang, X. Jiang, Z.-S. Yang and W.-J. Jiang, Ind. Eng. Chem. Res., 2015, 54, 1689-1696.

22 H. Guedidi, L. Reinert, J. Lévêque, Y. Soneda, N. Bellakhal and L. Duclaux, Carbon, 2013, 54, 432-443.

23 A. Boyano, M. E. Gálvez, R. Moliner and M. J. Lázaro, Fuel, 2008, 87, 2058-2068.

24 S. Yang, F. Qi, S. Xiong, H. Dang, Y. Liao, P. K. Wong and J. Li, Appl. Catal., B, 2016, 181, 570-580.

25 J. Li, N. Kobayashi and Y. Hu, J. Environ. Eng., 2007, 2, 740-751. 26 K. Jastrząb, Fuel Process. Technol., 2012, 101, 16-22.

27 Y. Guo, Z. Liu, Q. Liu and Z. Huang, Catal. Today, 2008, 131, 322-329.

28 K. Tsuji and I. Shiraishi, Fuel, 1997, 76, 555-560.

29 K. Jastrząb, Fuel Process. Technol., 2012, 104, 371-377.

30 Z. Yan, L. Liu, Y. Zhang, J. Liang, J. Wang, Z. Zhang and X. Wang, Energy Fuels, 2013, 27, 3080-3089.

31 C. Moreno, F. J. Maldonado and C. A. F. Pérez, Langmuir, 2003, 19, 5650-5655.

32 S. Mitsubishi, T. Seto, S. Mitsuoka and K. Inoue, European Pantent, EP0377483, 1990.

33 M. Descostes, F. Mercier, N. Thromat, C. Beaucaire and M. Gautier-Soyer, Appl. Surf. Sci., 2000, 165, 288-302.

34 V. Hayez, A. Franquet, A. Hubin and H. Terryn, Surf. Interface Anal., 2004, 36, 876-879.

35 C. Sun, Phys. Rev. B: Condens. Matter Mater. Phys., 2004, 69, 1129-1133.

36 E. Morris, C. Jia and K. Morita, Ind. Eng. Chem. Res., 2010, 49, 12709-12717.

37 G. Klinzing and R. Walker, Fuel, 1984, 63, 1450-1454.

38 J. M. Rosas, R. Ruiz-Rosas, J. Rodríguez-Mirasol and T. Cordero, Chem. Eng. J., 2017, 307, 707-721.

39 Z. Zhu, Z. Liu, H. Niu and S. Liu, J. Catal., 1999, 187, 245-248. 40 K. Saravanan, B. Tyagi and H. C. Bajaj, Catal. Sci. Technol., 2012, 2, 2512-2520.

41 P. Rowe, S. Neshyba and V. Walden, Opt. Express, 2011, 19, 5451-5463.

42 Y. Guo, Z. Liu, Y. Li and Q. Liu, J. Fuel Chem. Technol., 2007, 35, 344-348. 